\title{
Why does tobacco-control spending vary so much across states?
}

\author{
Michael L. Marlow
}

\begin{abstract}
Although tobacco-control spending is considered an essential component of comprehensive programmes aimed at lowering smoking, substantial variation exists across states. This article examines if variation is systematically related to cross-state differences in smoking prevalence, holding other factors constant that are expected to influence spending. An econometric model is estimated which considers effects of tobacco-settlement revenues, income, unemployment, political party of the governor, state debt and smoking prevalence on tobacco-control spending in all states during 2000-2007. Estimations control for the possibility that spending and smoking prevalence are co-determined to clearly determine the causal link from prevalence to spending. Spending variation is determined to be inconsistent with a 'rational needs' strategy whereby states with higher prevalence choose more funding than states with lower prevalence. This empirical result is consistent with recent studies indicating that spending on tobacco control exerts little to no effect on cigarette sales or smoking prevalence.
\end{abstract}

\section{Introduction}

Centers for Disease Control and Prevention (2007) considers tobacco-control spending an essential component of comprehensive programmes aimed at lowering smoking. CDC only began publishing data on spending in 2000 because many states did not actively fund programmes until after the Master Settlement Agreement in 1998. Table 1 displays selected summary statistics on annual per capita spending (\$2005) over 2000-2007 published by Campaign for Tobacco-Free Kids (2008). The simple average is $\$ 2.99$, and with a range from $\$ 0.00$ to $\$ 12.51$, substantial variation exists across states. Roughly, $\$ 5.3$ billion $(\$ 2005)$ has been spent on tobacco control over this period.

If variation is systematically related to factors that reflect urgency of public health concerns, such as differences in smoking prevalence, then variation may simply represent efficient resource allocations across states. If spending is positively related to prevalence, then spending variation suggests that funding flows towards highest valued uses and is consistent with lowering prevalence within the nation as a whole. However, an inverse relation may signal a public health problem because states with lower smoking prevalence allocate funds more generously than states with higher prevalence. Lack of any systematic relationship may also signal a public health problem because spending variation is unrelated to smoking prevalence and so funding does not flow towards high. est valued uses.

The issue of what determines tobacco-control spending is especially important for the fundamental question of whether tobacco-control spending exerts a significant effect on cigarette consumption. Hu ct al. (1995a, b) found that California's tobacco-control spending in the late 1980s significantly lowered consumption. Farrelly et al. (2003) and Tauras et al. (2005) found that spending significantly lowered smoking from 1981 to 2000 in all 50 states. Other studies cast doubt on whether spending effectively lowers consumption. Marlow (2006) examined spending of all states during 
Table 1. Annual per capita state spending (\$2005) on tobacco control over 2000-2007

\begin{tabular}{|c|c|c|c|c|c|c|c|c|c|}
\hline & Mean & Median & Minimum & Maximum & & Mean & Median & Minimum & Maximum \\
\hline AK & 5.92 & 6.11 & 2.44 & 8.61 & MT & 3.62 & 3.52 & 0.44 & 6.96 \\
\hline $\mathrm{AL}$ & 0.45 & 0.11 & 0.07 & 1.53 & $\mathrm{NC}$ & 0.91 & 1.05 & 0.00 & 1.79 \\
\hline$A R$ & 5.50 & 6.37 & 0.00 & 6.97 & ND & 3.44 & 4.44 & 0.00 & 4.87 \\
\hline $\mathrm{AZ}$ & 4.98 & 4.01 & 3.48 & 7.30 & $\mathrm{NE}$ & 2.87 & 2.97 & 0.24 & 4.63 \\
\hline $\mathrm{CA}$ & 2.80 & 2.63 & 2.06 & 4.18 & $\mathrm{NH}$ & 1.30 & 1.24 & 0.00 & 2.74 \\
\hline $\mathrm{CO}$ & 2.95 & 3.11 & 0.85 & 5.49 & NJ & 2.36 & 1.89 & 1.20 & 3.89 \\
\hline $\mathrm{CT}$ & 0.34 & 0.18 & 0.01 & 1.33 & NM & 2.58 & 2.79 & 1.39 & 3.71 \\
\hline $\mathrm{DE}$ & 5.68 & 5.23 & 0.00 & 12.62 & NV & 1.84 & 1.87 & 1.41 & 2.19 \\
\hline FL & 1.35 & 1.12 & 0.05 & 3.11 & NY & 2.30 & 2.12 & 1.73 & 4.20 \\
\hline GA & 1.56 & 1.76 & 0.23 & 2.63 & $\mathrm{OH}$ & 4.10 & 3.86 & 2.06 & 5.99 \\
\hline $\mathrm{HA}$ & 6.94 & 7.18 & 3.71 & 9.08 & OK & 1.56 & 1.68 & 0.53 & 2.62 \\
\hline IA & 2.49 & 1.95 & 1.73 & 3.64 & OR & 1.99 & 1.83 & 0.84 & 3.48 \\
\hline ID & 0.93 & 1.01 & 0.36 & 1.33 & PA & 2.64 & 3.11 & 0.00 & 4.48 \\
\hline IL & 1.68 & 0.99 & 0.63 & 3.96 & RI & 2.40 & 2.44 & 0.85 & 3.36 \\
\hline IN & 3.87 & 3.69 & 1.63 & 6.51 & $\mathrm{SC}$ & 0.30 & 0.43 & 0.00 & 0.51 \\
\hline $\mathrm{KS}$ & 0.25 & 0.21 & 0.19 & 0.35 & $\mathrm{SD}$ & 1.82 & 1.48 & 0.84 & 3.85 \\
\hline KY & 0.98 & 0.71 & 0.49 & 1.62 & $\mathrm{TN}$ & 0.00 & 0.00 & 0.00 & 0.00 \\
\hline LA & 1.58 & 1.80 & 0.12 & 2.51 & $\mathrm{TX}$ & 0.42 & 0.41 & 0.21 & 0.62 \\
\hline MA & 3.36 & 1.01 & 0.40 & 8.10 & UT & 2.88 & 2.88 & 2.58 & 3.13 \\
\hline MD & 3.95 & 3.59 & 1.59 & 6.40 & VA & 2.19 & 2.01 & 1.62 & 3.20 \\
\hline $\mathrm{ME}$ & 12.51 & 11.52 & 10.46 & 16.69 & VT & 9.12 & 8.37 & 7.52 & 12.08 \\
\hline MI & 0.00 & 0.00 & 0.00 & 0.00 & WA & 3.77 & 4.05 & 2.76 & 4.55 \\
\hline $\mathrm{MN}$ & 5.59 & 5.20 & 3.66 & 8.04 & WI & 2.75 & 2.44 & 1.69 & 4.47 \\
\hline $\mathrm{MO}$ & 0.00 & 0.00 & 0.00 & 0.00 & WV & 3.37 & 3.43 & 2.83 & 3.70 \\
\hline MS & 7.51 & 7.28 & 0.00 & 12.34 & WY & 5.99 & 6.27 & 1.97 & 11.15 \\
\hline
\end{tabular}

Source: Campaign for Tobacco-Free Kids (2008).

2001-2002 and found no significant effect on cigarette sales. Marlow (2007b) examined California's programme over 1989-2002 and found a trivial effect on cigarette sales. No relation between spending and prevalence over 2001-2005 in the 50 states was found in Marlow (2008). Marlow (2009) found no significant effect from spending on sales over 2000-2007 in all 50 states.

Table 2. Means (standard deviations) of variables (all states)

\begin{tabular}{lcccccccccc}
\hline & 2000 & 2001 & 2002 & 2003 & 2004 & 2005 & 2006 & 2007 \\
\hline Spending & 3.35 & 3.39 & 3.13 & 3.09 & 2.73 & 2.70 & 2.80 & 2.77 \\
& $(3.51)$ & $(3.42)$ & $(2.64)$ & $(2.79)$ & $(2.89)$ & $(2.73)$ & $(2.94)$ & $(2.96)$ \\
TS & 30.51 & 32.81 & 34.41 & 26.90 & 26.52 & 26.19 & 23.28 & 23.30 \\
& $(14.80)$ & $(15.72)$ & $(14.18)$ & $(9.95)$ & $(7.95)$ & $(7.96)$ & $(7.44)$ & $(7.52)$ \\
UE & 3.84 & 4.47 & 5.32 & 5.56 & 5.14 & 4.88 & 4.40 & 4.32 \\
& $(0.91)$ & $(0.87)$ & $(1.00)$ & $(1.04)$ & $(0.99)$ & $(1.06)$ & $(1.00)$ & $(1.01)$ \\
INCOME & 32126 & 32261 & 32171 & 32275 & 33067 & 33453 & 34233 & 35268 \\
& $(5003)$ & $(4825)$ & $(4654)$ & $(4517)$ & $(4722)$ & $(4900)$ & $(4996)$ & $(5234)$ & 256 \\
DEMOCRAT & 0.40 & 0.46 & 0.38 & 0.44 & 0.44 & 0.44 & 0.44 & 0.56 \\
& $(0.49)$ & $(0.71)$ & $(0.49)$ & $(0.50)$ & $(0.50)$ & $(0.50)$ & $(0.50)$ & $(0.50)$ \\
DEBT & 42.08 & 60.01 & 157.42 & 77.12 & 55.64 & 104.09 & 93.73 & 160.81 \\
& $(194.73)$ & $(179.47)$ & $(218.08)$ & $(233.42)$ & $(251.56)$ & $(281.35)$ & $(170.04)$ & $(240.36)$ \\
PREVALENCE1 & 17.80 & 17.73 & 18.41 & 17.42 & 16.06 & 15.64 & 15.20 & 14.98 \\
& $(3.00)$ & $(2.88)$ & $(3.26)$ & $(3.16)$ & $(2.87)$ & $(2.82)$ & $(2.90)$ & $(2.98)$ \\
PREVALENCE2 & 22.85 & 23.34 & 23.37 & 22.51 & 21.54 & 21.02 & 20.35 & 20.09 \\
& $(3.04)$ & $(2.98)$ & $(3.31)$ & $(3.34)$ & $(3.19)$ & $(3.16)$ & $(3.16)$ & $(3.19)$ \\
\hline
\end{tabular}

Notes: Spending. tobacco-control spending ( $\$ 2005)$ per capita; TS, tobacco-settlement funds (\$2005) per capita; UE, unemploy-
ment rate: Income, personal income $(\$ 2005)$ total state debt (\$2005) per capita; Prevalence 1 capita; Democrat, 1 if governor is Democrat; 0 otherwise; Debt, 1 year change in population who smoke 'every' day and 'some' days. 
Mixed evidence on whether spending significantly lowers tobacco use clearly indicates the importance of our study of the determinants of spending. This study examines the relation between smoking prevalence and spending over 2000-2007 across all 50 states, holding constant other factors that would be expected to influence spending. State spending is found to be inconsistent with a 'rational needs' strategy whereby states with greater public health concerns choose to fund programmes more generously than states with lesser problems.

\section{An Empirical Model of Spending}

Two studies have directly examined the determinants of state tobacco-control funding. Gross et al. (2002) studied spending in 2001 and concluded that state health issues exert little effect on state spending. This study also found an inverse relationship between smoking rates and tobacco-control spending, but its use of simple correlation analysis and stepwise regression does not clearly indicate the causal direction of this relationship. Marlow (2007a) examined state spending in 2001 and 2002 and, although no systematic effects from a variety of factors were uncovered in 2001, significant influences were found for tobacco-settlement funds (positive), unemployment rates (negative) and budget deficits (positive) in 2002. No relationship between spending and smoking prevalence was uncovered in either year. Examination of a longer time period would thus appear to determine what relationship, if any, exists between spending and smoking prevalence.

The theory behind using tobacco-control programmes to lower smoking prevalence is discussed in Marlow (2007a). As long as spending is believed to be inversely related to prevalence, and state officials seek to lower prevalence, an efficient allocation across states would yield a positive relation between spending and prevalence. States with higher smoking prevalence receive greater funding than states with lower prevalence, holding constant other factors that influence spending. Of course, this logic assumes that spending is equally effective in curbing prevalence across states and that states exhibit homogeneous policy objectives.

Endogeneity is a concern if, while prevalence influences spending under the 'rational needs' theory, spending may also influence prevalence when states exhibit different tolerances for smoking. States with high tolerance then may spend less on tobacco control than states exhibiting low tolerance simply because states with high tolerance view prevalence to be less of a problem than states with low tolerance. Although higher spending may cause lower prevalence, a counterinterpretation is that lower prevalence causes higher spending. Possibility of two-way causality between spending and prevalence is addressed by estimating models with and without two-stage least squares. Ordinary Least Squares (OLS) produces biased and inconsistent estimates of coefficients when endogeneity is a problem. If tolerance is an omitted variable. and tolerance is positively correlated with prevalence, then the OLS estimator of the prevalence coeflicient will be biased upwards.

The following model of spending on tobacco control is estimated by a pooled regression model over 2000) 2007. Total sample size is 399 observations and includes all states except one observation (Hawaii) on prevalence in 2004 that does not exist. Table 2 displays summary statistics of the variables. All nominal dollar data are converted to $\$ 2005$ by using the consumer price index:

$$
\begin{array}{r}
\text { SPENDING }_{i t}=f\left(\mathrm{TS}_{\mathrm{it}}, \mathrm{UE}_{\mathrm{it}}, \text { INCOME }_{\mathrm{it}},\right. \\
\text { DEMOCRAT } \left._{\mathrm{it}}, \text { DEBT }_{\mathrm{it}}, \text { PREVALENCE }_{\mathrm{it}}\right)
\end{array}
$$

SPENDING $_{i t}$ refer to state per capita spending (\$2005) on tobacco-control programmes and was obtained from Campaign for Tobacco-Free Kids (2008). $\mathrm{TS}_{\mathrm{it}}$ are obtained from Orzechowski and Walker (2008) and refers to state per capita tobaccosettlement funds (\$2005) and are hypothesized to be positively related to spending based on expectation that some of these revenues fund tobacco control.

$\mathrm{UE}_{\mathrm{it}}$ are obtained from Bureau of Labor Statistics and refer to unemployment rates and control for economic condition of states. Higher values are expected to lower tobacco-control spending as officials raise spending on income-stabilization programmes that then crowds-out spending on tobacco control. Real (\$2005) per capita personal income, INCOME $E_{i 1}$ are obtained from Bureau of Labor Statistics and are hypothesized to be positively related to spending based on the expectation that tobacco control is a 'normal' good. DEBT it are obtained from the Census Bureau and refer to 1-year changes in state government debt per capita (\$2005) and control for the expectation that higher debt indicates greater fiscal duress that results in lower spending on tobacco control. DEMOCRAT $T_{i t}$ equals $I$ if a state had a Democratic governor and 0 otherwise to control for the possibility that spending priorities differ between political parties.

The per cent of the adult population who smoke. PREVALENCE $E_{\mathrm{it}}$, is based on data collected by the Behavioral Risk Factor Surveillance System. a telephone survey of health behaviours of the civilian. noninstitutionalized US population. 18 years old and over. Two measures are considered: PREV ALENCE $I_{\text {it }}$ measures per cent of 'every' day smokers and PREVALENCE2 ${ }_{\mathrm{it}}$ measures per cent of 'every' day 
plus 'sometimes' smokers. Expected signs on PREVALENCE $_{\mathrm{it}}$ are positive under the 'rational needs' allocation framework whereby states with higher prevalence spend more than states with lesser needs. Both measures of prevalence are separately considered because it is unclear which measure is more important to policy makers. It is possible that prevalence influences spending with a lag when, for example budgets are based on the previous year's estimate of prevalence. However, when estimations of spending equations were run with 1-year lagged prevalence, results did not vary with those without lags, and so these alternative estimations are not displayed.

To control for possible endogeneity between PREVALENCE $_{i t}$ and SPENDING $_{i t}$, an instrumental variable for PREVALENCE $\mathrm{it}_{\mathrm{it}}$ is separately considered in two-stage least square regressions. Valid instruments are correlated with the prevalence variable, but not with the error term of the spending equation. Instruments include all the independent variables in Equation 1 except for PREVALENCE ${ }_{\text {it }}$ plus a dichotomous variable that equals 1 if the state has a significant tobaccomanufacturing presence (Georgia, Kentucky, North Carolina, Ohio, South Carolina, and Virginia) and 0 otherwise. Stock and Watson (2003) suggest that a simple rule of thumb to check for weak instruments: to demonstrate that the $F$-statistic exceeds 10 when testing the hypothesis that coefficients on all instruments are zero. F-statistics of $31.3(p<0.001)$ for PREVALENCE $1_{\text {it }}$ instruments, and of 28.6 $(p<0.001)$ for PREVALENCE $2_{i t}$ instruments, indicates that these are not weak instruments. In regressions of PREVALENCE $1_{i t}$, the estimated coefficient on tobacco-manufacturing presence is $2.66(t=6.273$, $p<0.001)$ and in regressions of PREVALENCE $2_{\text {it }}$ the estimated coefficient on tobacco-manufacturing presence is $2.65(t=5.483, p<0.001)$, and so prevalence is significantly higher in states with significant tobacco industry presence.

\section{Results and Discussion}

OLS estimates are displayed in columns (1) and (3) of Table 3 and indicate significant influences from tobaccosettlement funds (positive), unemployment (negative), income (negative), Democrat governor (positive), debt (negative) and both measures of prevalence (negative). Two-Stage Least Squares (TSLS) estimates in columns (2) and (4) indicate similar significant influences except unemployment which exerts no significant influence in column (4). OLS and TSLS estimates mirror each other except that, as noted below, coefficients on prevalence variables in TSLS estimations differ from OLS estimations by a magnitude of roughly 3 .

States spend 11-13 cents of each dollar received from tobacco-settlement funds. States with Democratic governors spend \$1.21-\$1.36 more than states with Republican governors. An extra dollar of debt lowers tobacco-control spending by only $\$ 0.001$. Estimated coefficients on prevalence indicate that states do not follow a 'rational needs' approach to budgeting. OLS estimates indicate spending falls (rises) by 11-12 cents for every percentage point increase (decrease) in PREVALENCE $1_{\text {it }}$ and PREVALENCE2 ${ }_{\text {it }}(p=0.021$ and $p=0.007$, respectively). TSLS estimates indicate the same direction, but effects are roughly three times larger: spending falls (rises) by 34 cents for every percentage point in prevalence ( $p=0.040$ for both measures of prevalence). $p$-Values are lower in TSLS estimations and this commonly occurs because standard errors are biased downwards in OLS estimations when endogeneity is present. If tolerance is an omitted variable, and tolerance is positively correlated with prevalence, then the OLS estimator of the prevalence

Table 3. Spending on tobacco control in all states-estimated coefficients ( $p$-values)

\begin{tabular}{lllcc}
\hline & $(1)$ & $(2)$ & $(3)$ & \multicolumn{1}{l}{ (4) } \\
Explanatory variables & OLS & TSLS & OLS & TSLS \\
\hline TS & $0.099814(<0.001)$ & $0.112232(<0.001)$ & $0.100558(<0.001)$ & $0.112656(<0.001)$ \\
UE & $-0.377533(0.003)$ & $-0.297224(0.034)$ & $-0.350944(0.005)$ & $-0.234257(0.130)$ \\
INCOME & $-7.94 \mathrm{E}-05(0.011)$ & $-0.000142(0.008)$ & $-8.14 \mathrm{E}-05(0.008)$ & $-0.000139(0.008)$ \\
DEMOCRAT & $1.212395(<0.001)$ & $1.358667(<0.001)$ & $1.214776(<0.001)$ & $1.346031(<0.001)$ \\
DEBT & $-0.001105(0.069)$ & $-0.001304(0.041)$ & $-0.001092(0.071)$ & $-0.001241(0.049)$ \\
PREVALENCE1 & $-0.111764(0.021)$ & $-0.338872(0.040)$ & & \\
PREVALENCE2 & & & $-0.123417(0.007)$ & $-0.341252(0.039)$ \\
Constant & $6.034649(<0.001)$ & $11.09931(0.004)$ & $6.790722(<0.001)$ & $12.524405(0.006)$ \\
Observations & 399 & 399 & 399 & 399 \\
$F$-statistic $(p$-value) & $17.343(<0.001)$ & $17.161(<0.001)$ & $17.762(<0.001)$ & $17.161(<0.001)$ \\
$R^{2}$ (adjusted) & 0.1977 & 0.1524 & 0.2018 & 0.1549 \\
Mean dependent variable & 2.9828 & 2.9828 & 2.9828 & 2.9828 \\
\hline
\end{tabular}


coefficient will be biased upwards. These results are therefore consistent with this concern and it is appropriate to use TSLS estimation.

Table 4 displays estimates from the 46 states that participated in the tobacco-settlement agreement. Results mirror those of Table 3 with the following exceptions. Unemployment no longer exerts a significant influence in column (2). OLS estimates indicate that spending falls (rises) by 13 cents for every percentage point increase (decrease) in PREVALENCE1 $1_{i t}$ and PREVALENCE2 $2_{\text {it }}$ $(p=0.008$ and $p=0.005$, respectively). Estimates from TSLS again exhibit larger effects: spending falls (rises) by 38 cents for every percentage point increase (decrease) in PREVALENCE $1_{\text {it }}$ and PREVALENCE $2_{\text {it }}(p=0.021$ and $p=0.031$, respectively). These results are consistent with those of the previous table indicating that the OLS estimator of the prevalence coefficient is biased upwards and it is appropriate to use TSLS estimation.

It remains possible that the inverse relation between spending and prevalence is somehow related to the expectation that states spend more on tobacco control have lower prevalence because of spending programmes. One way of dealing with this possibility is to exclude from analysis those states with long-standing tobacco-control programmes based on the expectation that newer programmes are less effective in lowering prevalence because effects are incremental in nature and take many years to exert desired effects. Table 5 displays the estimates of tobacco-control spending excluding states with long-standing programmes Arizona, California, Massachusetts and Oregon. Whereas results mirror those of previous tables, it is interesting that $p$-values associated with prevalence variables indicate that, while still negative and roughly of the same magnitudes, coefficients are less statistically significant in TSLS estimations: PREVALENCE ${ }_{\text {i }}$ $(p=0.072)$ and PREVALENCE $2_{i t}(p=0.071)$. These estimations suggest that the relationship between spending and prevalence in states with newer tobaccocontrol programmes is either weakly negative or zero and therefore continue to offer no support for the 'rational needs' hypothesis.

Table 4. Spending on tobacco control (46 states participating in tobacco settlement) estimated coefficients ( $p$-values)

\begin{tabular}{|c|c|c|c|c|}
\hline Explanatory variables & $\begin{array}{l}(1) \\
\text { OLS }\end{array}$ & $\begin{array}{l}\text { (2) } \\
\text { TSLS }\end{array}$ & $\begin{array}{l}\text { (3) } \\
\text { OLS }\end{array}$ & $\begin{array}{l}\text { (4) } \\
\text { TSLS }\end{array}$ \\
\hline TS & $0.112771(<0.001)$ & $0.129677(<0.001)$ & $0.112845(<0.001)$ & $0.129741(<0.001)$ \\
\hline UE & $-0.287762(0.031)$ & $-0.192736(0.199)$ & $-0.264853(0.049)$ & $-0.127576(0.437)$ \\
\hline Income & $-8.48 \mathrm{E}-05(0.007)$ & $-0.000153(0.005)$ & $-8.35 \mathrm{E}-05(0.007)$ & $-0.000148(0.005)$ \\
\hline Democrat & $1.145188(<0.001)$ & $1.304760(<0.001)$ & $1.144965(<0.001)$ & $1.302695(<0.001)$ \\
\hline Debt & $-0.001288(0.0412)$ & $-0.001545(0.022)$ & $-0.001251(0.047)$ & $-0.001435(0.031)$ \\
\hline Prevalence 1 & $-0.132756(0.008)$ & $-0.384757(0.021)$ & & \\
\hline Prevalence 2 & & & $-0.133020(0.005)$ & $-0.383270(0.031)$ \\
\hline Constant & $5.987083(<0.001)$ & $11.48684(0.003)$ & $6.526317(<0.001)$ & $12.99149(0.004)$ \\
\hline Observations & 367 & 367 & 367 & 367 \\
\hline$F$-statistic ( $p$-value) & $15.417(<0.001)$ & $15.142(<0.001)$ & $15.625(<0.001)$ & $14.142(<0.001)$ \\
\hline$R^{2}$ (adjusted) & 0.1912 & 0.13414 & 0.1934 & 0.1294 \\
\hline Mean dependent variable & 3.0823 & 3.0823 & 3.08234 & 3.0823 \\
\hline
\end{tabular}

(ptates with long-standing programmes) estimated coeflicients (p-ralues)

Table 5. Spending on tobacco control (excluding states with long-standing programmes) estimatedcocfrcis (4)

\begin{tabular}{|c|c|c|c|c|}
\hline Explanatory variables & $\begin{array}{l}\text { (1) } \\
\text { OLS }\end{array}$ & $\begin{array}{l}(2) \\
\text { TSLS }\end{array}$ & $\begin{array}{l}(3) \\
\text { OLS }\end{array}$ & $\begin{array}{l}\text { (4) } \\
\text { TSLSS }\end{array}$ \\
\hline TS & $0.098987(<0.001)$ & $0.109306(<0.001)$ & $0.100009(<0.001)$ & $0.110258(<0 .(0) 1)$ \\
\hline UE & $-0.376604(0.006)$ & $-0.235538(0.182)$ & $-0.340877(0.014)$ & $\begin{array}{l}-0.158972(0.438) \\
-0.000132(0.018)\end{array}$ \\
\hline Income & $-7.46 \mathrm{E}-05(0.023)$ & $-0.000138(0.019)$ & $-7.66 \mathrm{E}-05(0.017)$ & \\
\hline Democrat & $1.299073(<0.001)$ & $1.501044(<0.001)$ & $1.304491(<0.001)$ & $\begin{array}{r}1.477053(<0.001) \\
-0.001403(0.043)\end{array}$ \\
\hline Debt & $-0.001252(0.058)$ & $-0.001510(0.033)$ & $-0.001233(0.061)$ & \\
\hline Prevalence 1 & $-0.105532(0.045)$ & $-0.358118(0.071)$ & $0123229(0.013)$ & $-0.360019(0.071)$ \\
\hline Prevalence 2 & & $1806827(0.013)$ & $\begin{aligned}-0.123229 & (0.015) \\
6.519044 & (<0.001)\end{aligned}$ & $12.38132(0.016)$ \\
\hline Constant & $5.707857(<0.001)$ & $11.06827(0.013)$ & 367 & 367 \\
\hline Observations & 367 & $367744(<0.00)$ & $17.335(<0.001)$ & $16.744(<0.001)$ \\
\hline$F$-statistic ( $p$-value) & $16.866(<0.001)$ & $16.744(<0.00)$ & 0.2112 & 0.1606 \\
\hline$R^{2}$ (adjusted) & 0.2064 & $\begin{array}{l}0.1554 \\
2.9567\end{array}$ & 2.9567 & 2.9567 \\
\hline
\end{tabular}




\section{Conclusions}

Results do not support predictions of a 'rational needs' approach to funding. Holding constant other factors that influence spending, per capita annual spending (\$2005) on tobacco control is found to fall (rise) by $34-38$ cents for every percentage point increase (decrease) in prevalence. This inverse relationship arises in both estimations that do and do not correct for the possibility that states with less tolerance towards smoking will also spend more on tobacco control. These results suggest that spending variation across states does not reflect scarce funding dollars flowing towards highest valued uses.

The empirical analysis also makes it difficult to argue that spending lowers prevalence, despite some studies concluding this causal flow. As discussed, more recent studies find little to no connection from spending on consumption or prevalence thus suggesting a reason connected to the main result of this article: funding does not systematically flow to those states with the highest smoking prevalence. Further research into these matters would appear to be in order.

\section{References}

Cimpaign for Tobacco-Free Kids. (2008) History of State Spending for Tobacco Prevention, Campaign for Tobacco-Free Kids, Washington, DC.

Centers for Disease Control and Prevention. (2007) Best Practices for Comprehensive Tobacco Control Programs 2007, October 2007, US Department of Health and Human Services, Centers for Disease Control and
Prevention, National Center for Chronic Disease Prevention and Health Promotion, Office on Smoking and Health, Atlanta.

Farrelly, M. C., Pechacek, T. F. and Chaloupka, F. J. (2003) The impact of tobacco control program expenditures on aggregate cigarette sales: 1981-2000, Journal of Health Economics, 22, 843-59.

Gross, C. P., Soffer, B., Bach, P. B., Rajkumar, R. and Forman, H. P. (2002) State expenditures for tobacco-control programs and the tobacco settlement, New England Journal of Medicine, 347, 1080-6.

Hu, T., Sung, H. and Keeler, T. E. (1995a) Reducing cigarette consumption in California: tobacco taxes vs. an anti-smoking media campaign, American Journal of Public Health, 85, 1218-22.

Hu, T., Sung, H. and Keeler, T. E. (1995b) The state antismoking campaign and the industry response: the effects of advertising on cigarette consumption in California, American Economic Review, 85, 85-90.

Marlow, M. L. (2006) Tobacco control programs and tobacco consumption, Cato Journal, 26, 573-91.

Marlow, M. L. (2007a) Determinants of state tobacco-control spending, Applied Economics, 40, 831-9.

Marlow, M. L. (2007b) Do tobacco-control programs lower tobacco consumption? Evidence from California, Public Finance Review 35, 689-709.

Marlow, M. L. (2008) Do expenditures on tobacco control decrease smoking prevalence?, Applied Economics, 40 , 831-9.

Marlow, M. L. (2009) Is the CDC blowing smoke?, Regulation, 32, 46-52.

Orzechowski, W. and Walker, R. (2008) The Tax Burden on Tobacco, Orzechowski and Walker, Arlington, VA.

Stock, J. H. and Watson, M. W. (2003) Introduction to Econometrics, Addison-Wesley, Boston, MA.

Tauras, J. A., Chaloupka, F. J. and Farrelly, M. C. (2005) State tobacco control spending and youth smoking, American Journal of Public Health, 95, 338-44. 